Received: December, 2016

Accepted: March, 2017

ISSN $2006-6996$

\title{
EVALUATION OF ASYMMETRY USING THUMBPRINT MINUTIAE AMONG HAUSA POPULATION OF KANO STATE, NIGERIA
}

\author{
Adamu, L. H. ${ }^{1 *}$, Ojo, S.A., ${ }^{2}$ Danborno, B., ${ }^{3}$ Adebisi, S. S. and ${ }^{3}$ Taura, M. G. ${ }^{1,4}$ \\ ${ }^{1}$ Department of Anatomy, Faculty of Basic Medical Sciences, Bayero University, P M B 3011 Kano, Kano State, \\ Nigeria \\ ${ }^{2}$ Department of Veterinary Anatomy, Faculty of Veterinary Medicine, Ahmadu Bello University, Zaria, P M B 1045 \\ Samaru Zaria, Kaduna State, Nigeria \\ ${ }^{3}$ Department of Human Anatomy, Faculty of Medicine, Ahmadu Bello University, Zaria, P M B 1045 Samaru Zaria, \\ Kaduna State, Nigeria \\ ${ }^{4}$ Department of Anatomy College of Medicine, University of Bisha Saudi Arabia \\ * Corresponding author: alhassan.ana@buk.edu.ng
}

\section{ABSTRACT}

The present study was aimed at determining the existence of FA in Hausa populations using thumbprint minutiae. The participants included 112 males and 105 females of Hausa Ethnic descent, aged between 18-25 years. The minutiae of the plain thumbprints were determined from a circle with radius that cut across the nucleus of the fingerprints. The result showed that in signed asymmetry bifurcation, crossbar, break, point/dot into ridges and point/dot between ridges exhibited sexual dimorphism. The left ward asymmetry in male was exhibited in bifurcation, cross bar, trifurcation bifurcation, break, bridge, opposite bifurcation, in " $M$ " convergence, in " $M$ " bifurcation and Point/Dot into ridges. Similarly, in female bifurcation, trifurcation bifurcation, enclosure big, opposite bifurcation, convergence, in " $M$ " bifurcation and return exhibit left ward asymmetry. For absolute and composite asymmetry the significant differences was observed in end, enclosure (small), bridge and return. In the entire minutiae types only ridge bifurcation exhibited directional asymmetry in males and six other minutiae types in females. In conclusion, the presence of sexual dimorphism in thumbprint ridge minutiae was demonstrated in the present study. The leftward asymmetry was observed in both sexes in different types minutiae. Females were observed to exhibit directional type of asymmetry more than the males in this population. Keywords: Asymmetry, Environmental stress, Hausa population, Ridge minutiae, Sexual dimorphism,

\section{INTRODUCTION}

Different types of asymmetry exist in nature, these include directional asymmetry when one side of a bilateral structure is consistently larger than the other, antisymmetry when sides are consistently unequal in size, but neither side is more likely to be the largest (Graham et al., 1993). The third variety of asymmetry is fluctuating asymmetry (FA) which refers to random, subtle departures from perfect symmetry (Palmer and Strobeck, 1986). FA has become one of the useful tools in measuring developmental stability in structures that are normally symmetrical (Møller and Shykoff, 1999; Nijhout and Davidowitz, 2003). Of the three types of asymmetry, FA (Van Valen, 1962; Parsons 1990; Møller and Swaddle, 1997) and, under particular circumstances, directional asymmetry (Graham et al., 1998; Graham et al., 2003), are typically thought to be indicative of developmental instability and exposure to environmental stress during development.

Interestingly genetic factors may also have a weak relation to FA in fingerprints features (Martin et al., 1982; Arrieta et al., 1993). The genetic basis of differences in the small random variation usually found between the sides of the body of bilateral trait continues to be a subject of considerable interest in the literature. This can be applied to FA, a ubiquitous type of asymmetry that was reported to be one of those rare inheritable traits (Palmer et al., 1994). Thus the level of FA is expected to increase in group of individuals subjected to any of a variety of stressors. Based on the comparison of FA in stressed and non-stressed population it was suggested that direct genetic effects on FA itself are not responsible for any observed differences (Palmer et al., 1994). There is paucity of data regarding assessment of indicators of developmental instability in Hausa population. This may help in searching for possible factors that may lead to induction of stress and developmental instability in utero. It is now clear that the level of developmental instability and environmental stress may be assessed using FA in a given population (Palmer et al., 1994; Møller and Swaddle, 1997). The present study aimed at determining the existence of FA in Hausa populations using thumbprint minutiae.

\section{MATERIALS AND METHODS}

Study location and population

The study was conducted among one of the original Hausa States; Kano state of Nigeria. Kano is the most populous state in Nigeria (Barau, 2007). The urban area of the state covers $137 \mathrm{~km}^{2}$ and comprises of six local government areas (LGAs); Kano Municipal, Fagge, Dala, Gwale, Tarauni and Nassarawa (Figure 1). 
The principal inhabitants of the city are the Hausa people (Barau, 2007). A total of 217 subjects comprising 112 males and 105 females within the 1825 years of age participated in the study. Any subject who is Hausa up to level of grandfather, apparently healthy subject whose thumbs were free from any deformities or pathological changes were eligible for the study. Before the commencement of the research, Ethical approval was obtained from Ethical Committee of Ahmadu Bello University, Teaching Hospital, Zaria, Faculty of Medicine (ABUTHZ/HREC/506/2015) and Kano State Hospitals Management Board.

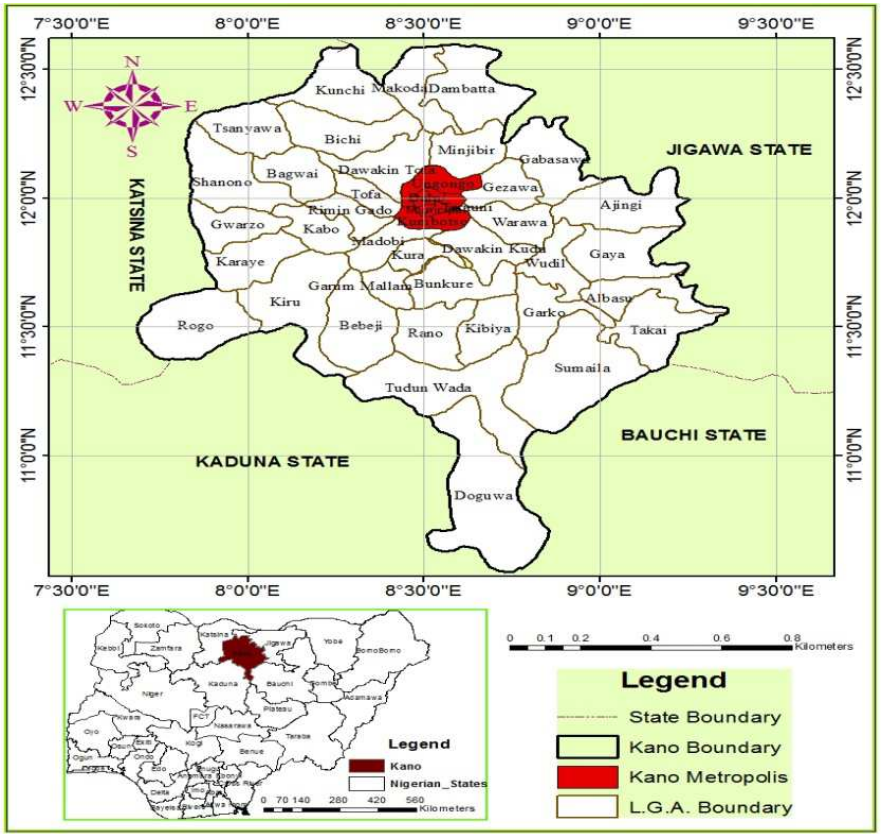

Figure 1: Map of the study area (Kano State).

Fingerprints Collection and Minutiae counts

Direct sensing fingerprints capturing method (Jain et al., 2007) was used to capture the plain fingerprints. For each thumbprint, two versions; the original size image (used for scaling) and amplified image (at ratio of 7.74); were captured using Bioanalyser (Microsoft visual basic version 6.0 programming language). These images were saved in jpeg format for variables reading in personal computer. The amplified thumbprint images were used for the thumbprint minutiae count.
The fingerprints were classified into any of the three basic patterns namely; arches, loops, whorls (Cummins and Midlo, 1943). The minutiae count was designed according to the method described by Okajima (1970), and the count were made using magnified images of thumbprint. The thumbprints were divided into two areas (center and periphery) by a circle with a diameter covering about 18 ridges. Only minutiae within the circle were counted (Figure 2). Sixteen different types (some with subtype) of minutiae (Table 1) were used (Champod and Margot, 1996; Gutierrez-Redomero et al., 2007).
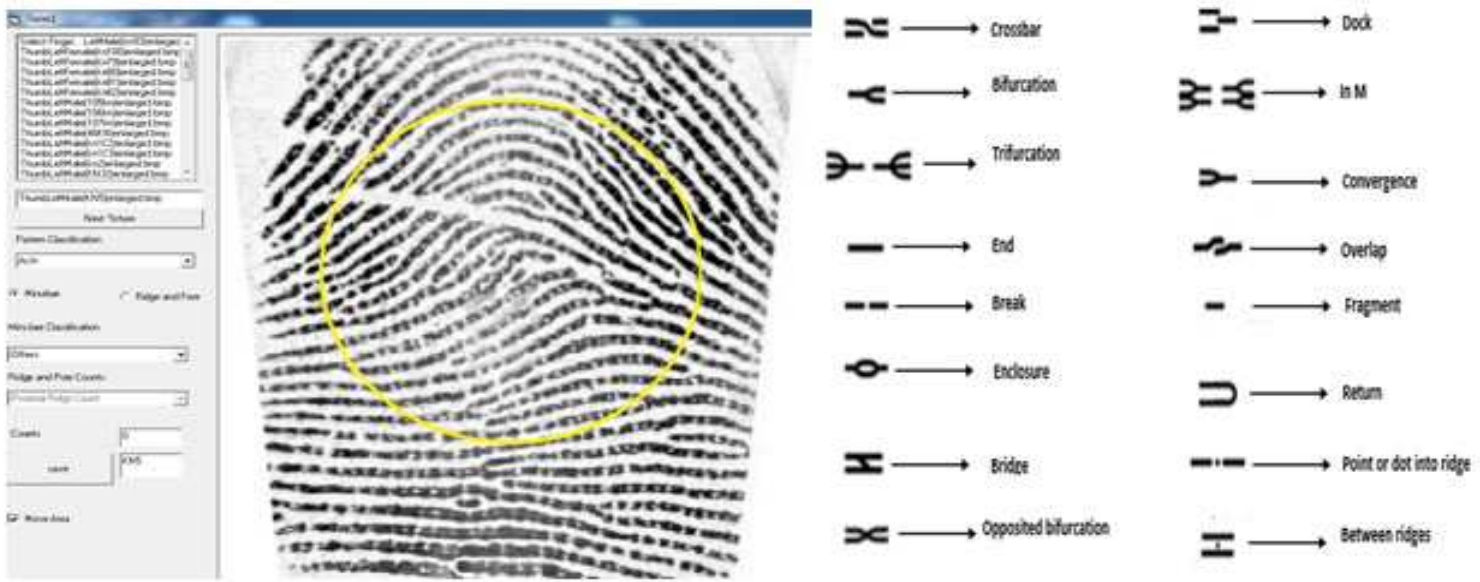

Figure 2: A Thumbprint Divided into Two Areas by a Circle for Determination of Different Types Of Minutiae 
BAJOPAS Volume 10 Number 1 June, 2017

Table 1: Different Types of Fingerprints Minutiae and Their Description

\begin{tabular}{ll}
\hline Minutiae type & Description \\
\hline Bifurcation & Minutiae form ridges to the right \\
Crossbar & Ridge that separates from its direction crossing between two others \\
Trifurcation & The minutiae form three ridges \\
End & Termination of a ridge \\
Break & Break in the ridge \\
Enclosure & The ridge path divides and then comes together again \\
Bridge & A short ridge crosses from one ridge to join the next \\
Opposite Bifurcation & Two ridges that join at one point \\
Dock & Crest end that enters between two other end ridges \\
In "M" convergence or & Two converged/ bifurcated ridges develop next to each other on the same ridge \\
bifurcation & \\
Convergence & Minutiae form ridges to the left \\
Overlap & Two ridge ends meet and overlap on a bias \\
Fragment & Short ridge with length equal or less ten times its width, \\
Return & The turning around of a ridge without being part of the nucleus \\
Point or dot into ridge & One ridge unit which contain only one sweat gland pores into ridge \\
Point or between ridges & One ridge unit which contain only one sweat gland pores between ridges \\
\hline
\end{tabular}

To determine systematic error in the minutiae counting the student paired t-test was performed to compare the means of the first and second counting using 30 randomly selected individuals. This allowed assessment of systematic error (bias error). Three indices of asymmetry, differences between left ( $L$ ) and right $(R)$ used included signed asymmetry (SA), absolute asymmetry (AA) and composite asymmetry $(C A)$. These were determined by the following formulae; $S A=R-L, A A=\sqrt{ }(R-L)^{2}, C A=\Sigma \sqrt{ }(R-L)$ $2 / n$, where $n$ is the sample size. The existence of directional asymmetry was detected by subjecting the mean value of signed asymmetry to one sample t-test (Manning, 1995; Palmer and Strobeck, 2003). An asymmetry was considered to be directional if mean value of signed symmetry differed significantly from zero, otherwise it was considered as FA. The data were expressed as mean \pm SD. ANOVA and
Independent sample $t$ test was used to test for differences between the areas of the thumb and sexual dimorphism respectively. SPSS version 20.0 statistical software was used for the statistical analysis and $P \leq 0.05$ was set as level of significance

\section{RESULTS}

From Table 2 the mean minutiae count showed variation between males and females. The significant differences were observed in ridge ending, enclosure, break, bridge, opposite bifurcation, in the right thumbprints. In the right thumbprints, the females had higher minutiae count only in break and bridge. With regards to the left thumbprints, the females had higher mean minutiae counts in the convergence and return. For males, significantly higher minutiae counts were observed in the bifurcation, cross bar, end, enclosure small and point or dot between ridges.

Table 2: Mean and Standard Deviation of Minutiae Count of Males and Females of both Left and Right Thumbs

\begin{tabular}{|c|c|c|c|c|c|c|c|c|c|c|c|c|}
\hline \multirow[b]{3}{*}{ Variables } & \multicolumn{5}{|c|}{ Right Thumb } & \multicolumn{5}{|c|}{ Left Thumb } & \multirow[b]{3}{*}{$\mathbf{t}$} & \multirow[b]{3}{*}{$\mathbf{P}$} \\
\hline & \multirow{2}{*}{$\begin{array}{l}\text { Male } \\
\text { Mean }\end{array}$} & \multicolumn{3}{|c|}{ Female } & \multirow[b]{2}{*}{$\mathrm{t}$} & \multirow[b]{2}{*}{$\mathrm{P}$} & \multirow{2}{*}{$\begin{array}{l}\text { Male } \\
\text { Mean }\end{array}$} & \multicolumn{3}{|c|}{ Female } & & \\
\hline & & SD & Mean & SD & & & & SD & Mean & SD & & \\
\hline Bifurcation & 2.97 & 2.21 & 3.10 & 2.10 & -0.45 & 0.654 & 3.94 & 2.85 & 3.13 & 2.47 & 2.21 & 0.0279 \\
\hline Cross bar & 0.05 & 0.23 & 0.08 & 0.30 & -0.63 & 0.530 & 0.15 & 0.51 & 0.03 & 0.17 & 2.38 & 0.0184 \\
\hline Trifurcation convergence & 0.04 & 0.19 & 0.04 & 0.24 & -0.08 & 0.934 & 0.03 & 0.16 & 0.02 & 0.14 & 0.38 & 0.7058 \\
\hline Trifurcation bifurcation & 0.01 & 0.09 & 0.03 & 0.17 & -1.06 & 0.289 & 0.06 & 0.24 & 0.05 & 0.26 & 0.42 & 0.6716 \\
\hline End & 5.08 & 3.61 & 3.17 & 2.53 & 4.48 & 0.001 & 4.88 & 3.45 & 2.65 & 2.21 & 5.64 & 0.0001 \\
\hline Break & 0.56 & 1.30 & 1.46 & 1.86 & -4.13 & 0.001 & 0.71 & 1.31 & 0.74 & 1.29 & -0.20 & 0.8433 \\
\hline Enclosure(big) & 1.31 & 1.43 & 0.88 & 1.14 & 2.42 & 0.016 & 1.12 & 1.33 & 1.05 & 1.07 & 0.42 & 0.6772 \\
\hline Enclosure(small) & 0.88 & 1.41 & 0.63 & 0.88 & 1.59 & 0.113 & 0.68 & 1.01 & 0.30 & 0.86 & 2.98 & 0.0032 \\
\hline Bridge & 0.15 & 0.41 & 0.46 & 0.94 & -3.14 & 0.002 & 0.21 & 0.54 & 0.39 & 0.89 & -1.86 & 0.0641 \\
\hline Opposite bifurcation & 0.17 & 0.44 & 0.04 & 0.19 & 2.81 & 0.005 & 0.20 & 0.44 & 0.19 & 0.44 & 0.13 & 0.8980 \\
\hline Dock & 0.06 & 0.34 & 0.06 & 0.23 & 0.14 & 0.892 & 0.02 & 0.13 & 0.05 & 0.25 & -1.09 & 0.2780 \\
\hline In "M" convergence & 0.00 & 0.00 & 0.09 & 0.52 & -1.74 & 0.083 & 0.04 & 0.19 & 0.05 & 0.21 & -0.42 & 0.6720 \\
\hline In "M" bifurcation & 0.04 & 0.19 & 0.02 & 0.14 & 0.73 & 0.464 & 0.08 & 0.27 & 0.05 & 0.21 & 0.98 & 0.3289 \\
\hline Convergence & 1.39 & 1.34 & 1.76 & 1.61 & -1.84 & 0.067 & 1.24 & 1.38 & 2.00 & 2.02 & -3.25 & 0.0014 \\
\hline Overlap & 0.29 & 0.62 & 0.19 & 0.42 & 1.43 & 0.153 & 0.15 & 0.38 & 0.17 & 0.47 & -0.34 & 0.7356 \\
\hline Fragment Big & 0.35 & 0.72 & 0.53 & 1.25 & -1.35 & 0.179 & 0.31 & 0.67 & 0.54 & 1.10 & -1.89 & 0.0608 \\
\hline Fragment Small & 0.63 & 1.40 & 0.59 & 1.24 & 0.24 & 0.809 & 0.50 & 1.05 & 0.33 & 1.17 & 1.07 & 0.2839 \\
\hline Return & 0.02 & 0.13 & 0.08 & 0.36 & -1.60 & 0.112 & 0.001 & 0.001 & 0.09 & 0.31 & -2.89 & 0.0042 \\
\hline Point or dot into ridge & 0.08 & 0.38 & 0.15 & 0.50 & -1.20 & 0.231 & 0.21 & 1.15 & 0.001 & 0.01 & 1.83 & 0.0682 \\
\hline Point or between ridges & 2.56 & 3.81 & 1.86 & 3.15 & 1.48 & 0.140 & 2.10 & 3.22 & 0.49 & 1.60 & 4.69 & 0.0001 \\
\hline
\end{tabular}


Sexual dimorphism assessments in the three indices of minutiae showed that in signed asymmetry bifurcation, crossbar, break, point/dot into ridges and point/dot between ridges exhibited sexual dimorphism (Table 2). For absolute asymmetry the significant sex differences was observed in cross bar, end, enclosure (small), bridge and return. Where significant sexual differences were observed the female had higher mean value ridge bridge and return only (Table 3 ). For composite asymmetry the significant sexual dimorphism in minutiae asymmetry was similar to what was observed in absolute asymmetry except for cross bar which also approaches significant (Table 4). The left ward asymmetry in male was exhibited in bifurcation, cross bar, trifurcation bifurcation, break, bridge, opposite bifurcation, in " $\mathrm{M}$ " convergence, in "M" bifurcation and Point/Dot into ridges. Similarly, in female bifurcation, trifurcation bifurcation, enclosure big, opposite bifurcation, convergence, in " $M$ " bifurcation and return exhibit left ward asymmetry (Table 2).

Table 3: Sexual Dimorphism in Signed Asymmetry of Thumbprint Minutiae

\begin{tabular}{lllll}
\hline Minutiae Types & Male & Female & & \\
& Mean \pm SD & Mean \pm SD & T & P value \\
\hline Bifurcation & $-0.96 \pm 3.02$ & $-0.03 \pm 2.94$ & -2.31 & 0.022 \\
Cross bar & $-0.10 \pm 0.57$ & $0.05 \pm 0.32$ & -2.3 & 0.022 \\
Trifurcation convergence & $0.01 \pm 0.21$ & $0.02 \pm 0.24$ & -0.33 & 0.742 \\
Trifurcation bifurcation & $-0.05 \pm 0.26$ & $-0.02 \pm 0.31$ & -0.89 & 0.376 \\
End & $0.20 \pm 4.65$ & $0.52 \pm 2.60$ & -0.64 & 0.526 \\
Break & $-0.14 \pm 2.00$ & $0.72 \pm 1.88$ & -3.28 & 0.001 \\
Enclosure (big) & $0.20 \pm 1.73$ & $-0.17 \pm 1.36$ & 1.73 & 0.084 \\
Enclosure (small) & $0.21 \pm 1.75$ & $0.33 \pm 1.13$ & -0.64 & 0.525 \\
Bridge & $-0.05 \pm 0.58$ & $0.07 \pm 1.11$ & -1.01 & 0.315 \\
Opposite bifurcation. & $-0.03 \pm 0.68$ & $-0.15 \pm 0.50$ & 1.55 & 0.123 \\
Dock & $0.04 \pm 0.37$ & $0.01 \pm 0.35$ & 0.72 & 0.473 \\
in "M" convergence & $-0.04 \pm 0.19$ & $0.04 \pm 0.57$ & -1.3 & 0.196 \\
in "M" bifurcation & $-0.04 \pm 0.34$ & $-0.03 \pm 0.26$ & -0.39 & 0.696 \\
Convergence & $0.15 \pm 1.89$ & $-0.24 \pm 2.35$ & 1.35 & 0.178 \\
Over lap & $0.14 \pm 0.70$ & $0.02 \pm 0.60$ & 1.40 & 0.164 \\
Fragment big & $0.04 \pm 1.01$ & $0.00 \pm 1.43$ & 0.27 & 0.789 \\
Fragment small & $0.14 \pm 1.35$ & $0.26 \pm 1.69$ & -0.55 & 0.582 \\
Return & $0.02 \pm 0.13$ & $-0.01 \pm 0.45$ & 0.62 & 0.538 \\
Point/Dot into ridges & $-0.13 \pm 1.22$ & $0.15 \pm 0.50$ & -2.16 & 0.032 \\
Point/Dot between ridges & $0.48 \pm 3.39$ & $1.39 \pm 3.38$ & -1.98 & 0.049 \\
\hline
\end{tabular}

Table 4: Sexual Dimorphism in Absolute Asymmetry of Thumbprint Minutiae

\begin{tabular}{lllll}
\hline Minutiae Types & Male & Female & & \\
& Mean \pm SD & Mean \pm SD & $t$ & P value \\
\hline Bifurcation & $2.29 \pm 2.18$ & $2.26 \pm 1.88$ & 0.10 & 0.918 \\
Cross bar & $0.21 \pm 0.54$ & $0.09 \pm 0.31$ & 1.98 & 0.049 \\
Trifurcation convergence & $0.04 \pm 0.21$ & $0.04 \pm 0.24$ & 0.22 & 0.829 \\
Trifurcation bifurcation & $0.07 \pm 0.26$ & $0.08 \pm 0.30$ & -0.13 & 0.90 \\
End & $3.55 \pm 2.98$ & $1.95 \pm 1.78$ & 4.76 & 0.001 \\
Break & $1.18 \pm 1.62$ & $1.35 \pm 1.49$ & -0.82 & 0.413 \\
Enclosure (big) & $1.21 \pm 1.24$ & $0.95 \pm 0.98$ & 1.72 & 0.088 \\
Enclosure (small) & $1.17 \pm 1.31$ & $0.66 \pm 0.98$ & 3.25 & 0.001 \\
Bridge & $0.27 \pm 0.52$ & $0.60 \pm 0.94$ & -3.26 & 0.001 \\
Opposite bifurcation. & $0.37 \pm 0.57$ & $0.23 \pm 0.47$ & 1.94 & 0.054 \\
Dock & $0.08 \pm 0.36$ & $0.10 \pm 0.34$ & -0.52 & 0.607 \\
in "M" convergence & $0.04 \pm 0.19$ & $0.13 \pm 0.56$ & -1.77 & 0.08 \\
in "M" bifurcation & $0.12 \pm 0.32$ & $0.07 \pm 0.25$ & 1.26 & 0.21 \\
Convergence & $1.44 \pm 1.23$ & $1.74 \pm 1.58$ & -1.59 & 0.112 \\
Over lap & $0.36 \pm 0.61$ & $0.27 \pm 0.54$ & 1.15 & 0.252 \\
Fragment big & $0.53 \pm 0.86$ & $0.76 \pm 1.21$ & -1.66 & 0.098 \\
Fragment small & $0.68 \pm 1.17$ & $0.81 \pm 1.51$ & -0.72 & 0.474 \\
Return & $0.02 \pm 0.13$ & $0.12 \pm 0.43$ & -2.48 & 0.014 \\
Point/Dot into ridges & $0.29 \pm 1.20$ & $0.15 \pm 0.50$ & 1.06 & 0.29 \\
Point/Dot between ridges & $2.25 \pm 2.57$ & $1.94 \pm 3.09$ & 0.8 & 0.425 \\
\hline
\end{tabular}


Table 5: Sexual Dimorphism in Composite Asymmetry of Thumbprint Minutiae

\begin{tabular}{|c|c|c|c|c|}
\hline \multirow[t]{2}{*}{ Minutiae Types } & Male & Female & \multirow[b]{2}{*}{$\mathrm{t}$} & \multirow[b]{2}{*}{$P$ value } \\
\hline & Mean \pm SD & Mean \pm SD & & \\
\hline Bifurcation & $0.02 \pm 0.02$ & $0.02 \pm 0.02$ & -0.43 & 0.669 \\
\hline Cross bar & $0.002 \pm 0.005$ & $0.001 \pm 0.003$ & 1.86 & 0.065 \\
\hline Trifurcation convergence & $0.0003 \pm 0.00$ & $0.0004 \pm 0.002$ & -0.13 & 0.894 \\
\hline Trifurcation bifurcation & $0.001 \pm 0.002$ & $0.001 \pm 0.003$ & -0.25 & 0.803 \\
\hline End & $0.03 \pm 0.03$ & $0.02 \pm 0.02$ & 4.30 & $<0.001$ \\
\hline Break & $0.01 \pm 0.01$ & $0.01 \pm 0.01$ & -1.21 & 0.228 \\
\hline Enclosure (big) & $0.01 \pm 0.01$ & $0.01 \pm 0.01$ & 1.27 & 0.206 \\
\hline Enclosure (small) & $0.01 \pm 0.01$ & $0.01 \pm 0.01$ & 2.91 & 0.004 \\
\hline Bridge & $0.002 \pm 0.005$ & $0.01 \pm 0.01$ & -3.47 & 0.001 \\
\hline Opposite bifurcation. & $0.00 \pm 0.01$ & $0.002 \pm 0.004$ & 1.68 & 0.094 \\
\hline Dock & $0.00 \pm 0.003$ & $0.001 \pm 0.003$ & -0.64 & 0.521 \\
\hline in "M" convergence & $0.0003 \pm 0.00$ & $0.001 \pm 0.01$ & -1.81 & 0.072 \\
\hline $\begin{array}{l}\text { in "M" bifurcation } \\
\text { Convergence }\end{array}$ & $\begin{array}{l}0.001 \pm 0.003 \\
0.01 \pm 0.01\end{array}$ & $\begin{array}{l}0.001 \pm 0.002 \\
0.02 \pm 0.02\end{array}$ & $\begin{array}{l}1.12 \\
-2.11\end{array}$ & $\begin{array}{l}0.266 \\
0.036\end{array}$ \\
\hline $\begin{array}{l}\text { Over lap } \\
\text { Fragment big } \\
\text { Fragment small }\end{array}$ & $\begin{array}{l}0.003 \pm 0.01 \\
0.005 \pm 0.01 \\
0.01 \pm 0.01\end{array}$ & $\begin{array}{l}0.003 \pm 0.01 \\
0.01 \pm 0.01 \\
0.01 \pm 0.01\end{array}$ & $\begin{array}{l}0.90 \\
-1.94 \\
-0.97\end{array}$ & $\begin{array}{l}0.37 \\
0.054 \\
0.332\end{array}$ \\
\hline $\begin{array}{l}\text { Return } \\
\text { Point/Dot into ridges } \\
\text { Point/Dot between ridges }\end{array}$ & $\begin{array}{l}0.0002 \pm 0.001 \\
0.00 \pm 0.01 \\
0.02 \pm 0.02\end{array}$ & $\begin{array}{l}0.001 \pm 0.004 \\
0.00 \pm 0.00 \\
0.02 \pm 0.03\end{array}$ & $\begin{array}{l}-2.52 \\
0.97 \\
0.45\end{array}$ & $\begin{array}{l}0.013 \\
0.333 \\
0.657\end{array}$ \\
\hline
\end{tabular}

Using one sample $t$ test only bifurcation exhibit directional asymmetry $(p<0.05)$ in male and six different minutiae types; end, break, enclosure small, point/dot into ridges and point/dot between ridges, in female (Table $6)$.

Table 6: One Sample t-test in for Evaluation of Fluctuation Asymmetry

\begin{tabular}{|c|c|c|c|c|c|c|c|c|}
\hline \multirow[b]{2}{*}{ Minutiae Types } & \multicolumn{3}{|c|}{ Male } & \multicolumn{4}{|c|}{ Female } & \multirow[b]{2}{*}{$P$ value } \\
\hline & Mean & SEM & $\mathrm{t}$ & $P$ value & Mean & SEM & $\mathrm{t}$ & \\
\hline Bifurcation & -0.96 & 0.285 & -3.383 & 0.001 & -0.03 & 0.287 & -0.099 & 0.921 \\
\hline Cross bar & -0.1 & 0.054 & -1.827 & 0.07 & 0.05 & 0.031 & 1.517 & 0.132 \\
\hline Trifurcation C & 0.01 & 0.02 & 0.446 & 0.657 & 0.02 & 0.023 & 0.815 & 0.417 \\
\hline Trifurcation B & -0.05 & 0.025 & -2.156 & 0.033 & -0.02 & 0.03 & -0.631 & 0.53 \\
\hline End & 0.2 & 0.439 & 0.447 & 0.656 & 0.52 & 0.253 & 2.069 & 0.041 \\
\hline Break & -0.14 & 0.189 & -0.756 & 0.451 & 0.72 & 0.184 & 3.938 & $<0.001$ \\
\hline Enclosure big & 0.20 & 0.163 & 1.203 & 0.232 & -0.17 & 0.133 & -1.29 & 0.2 \\
\hline Enclosure small & 0.21 & 0.165 & 1.245 & 0.216 & 0.33 & 0.11 & 3.017 & 0.003 \\
\hline Bridge & -0.05 & 0.055 & -0.973 & 0.333 & 0.07 & 0.108 & 0.614 & 0.54 \\
\hline Opposite B & -0.03 & 0.064 & -0.419 & 0.676 & -0.15 & 0.048 & -3.15 & 0.002 \\
\hline Dock & 0.04 & 0.034 & 1.295 & 0.198 & 0.01 & 0.034 & 0.276 & 0.783 \\
\hline in "M" C & -0.04 & 0.018 & -2.028 & 0.045 & 0.04 & 0.056 & 0.684 & 0.495 \\
\hline in "M" B & -0.04 & 0.032 & -1.393 & 0.167 & -0.03 & 0.025 & -1.135 & 0.259 \\
\hline Convergence & 0.15 & 0.179 & 0.85 & 0.397 & -0.24 & 0.229 & -1.039 & 0.301 \\
\hline Over lap & 0.14 & 0.066 & 2.173 & 0.032 & 0.02 & 0.059 & 0.323 & 0.747 \\
\hline Fragment Big & 0.04 & 0.095 & 0.469 & 0.64 & 0.001 & 0.139 & 0.001 & 1.00 \\
\hline Fragment Small & 0.14 & 0.127 & 1.122 & 0.264 & 0.26 & 0.165 & 1.556 & 0.123 \\
\hline Return & 0.02 & 0.013 & 1.421 & 0.158 & -0.01 & 0.044 & -0.217 & 0.828 \\
\hline Point/Dot into R. & -0.13 & 0.116 & -1.081 & 0.282 & 0.15 & 0.048 & 3.15 & 0.002 \\
\hline Point/Dot between $\mathrm{R}$. & 0.48 & 0.32 & 1.507 & 0.135 & 1.39 & 0.329 & 4.221 & $<0.001$ \\
\hline
\end{tabular}

C; convergence, B; Bifurcation, R; ridge, SEM; standard error of mean 


\section{DISCUSSION}

In population studies, thumb record higher bilateral asymmetry and large individual variation than any other finger (Malhotra et al., 1991). It is to be mentioned here that the thumb is given particular importance in the evolutionary history of man (Kusuma et al., 2001). Considering these advantages exhibited by thumb, this study assessed the asymmetry in ridge minutiae using thumbprints.

The presence of sexual dimorphism in the three different types of thumbprint minutiae may indicate differences in the responses to environmental stress encounter by developing organisms. It was reported that dermatoglyphic asymmetries are related to adult testosterone (Jamison et al., 1993). In another separate study pregnant Rhesus positive mothers exposed to testosterone tend to have offspring with fewer dermal ridges than controls (Jamison et al., 1994). Since men have higher average ridge number than women it is generally suggested that higher levels of androgens may lead to an increased complexity in ridge patterns and a higher ridge count (Mustanski et al., 2002). This may explain possible variation of the ridge minutiae between male and female in this population.

Number of studies reported that the ridges of right hand were found to be coarser than the left hand (Cummins et al., 1994). It was evident that left hand have greater number of ridges than in the right (Gutie' rrez-Redomero et al., 2007) and finer ridges than the right fingers (Mundorff et al., 2014). But these observations may be influenced by sex (Gutie' rrez-Redomero et al., 2007). It was suggested that if low asymmetry and sexual dimorphism in favor of male indicates the same aspects of mate quality then the ability to produce large traits in males should be correlated to the ability to produce symmetrical traits, leading to inverse relationship between asymmetry and trait size (Møller and Cuervo, 2003; Koehler et al, 2004). It was reported that male in the same (Hausa) population tend to have larger trait size compared to females including hands parameters (Umar et al., 2016). Therefore, the low asymmetry observed in males in this study is supported. However, higher asymmetry in some of minutiae indices was also observed in males in this study. It may be hypothesized that only minutiae that depends on finger size and or/ masculinity respond to effect of testosterone. This is due to the fact that level of testosterone correlated positively with symmetry and fingerprint ridges (Jamison et al., 1994). That leads to expression of low asymmetry in male compared to females.

During embryogenesis developing organism encounter different types of challenges from its environment. This led to manifestation of permanent signs in the adult body as a result of genetic and external

\section{REFERENCES}

Arrieta, M., Criado, B., Martinez, B., Lobato, M., Gil, A. and Lostao C. (1993). Fluctuating dermatoglyphic asymmetry: genetic and prenatal influences. Annals Human Biology, 20:557-563 perturbations in the environment. One of the manifestations includes small deviations from perfect symmetry in bilateral structure which correlates negatively with the amount of stress experienced during development (Siegel and Smookler, 1973; Siegel et al., 1977; Mooney et al., 1985). Many factors such as extreme temperatures, environmental pollution, population density, and inbreeding among others are reported to be potential stressors encountered by developing organisms (Parsons, 1992; Markow and Martin, 1993; Galeotti et al., 2005; Velickovic, 2007; Lewis et al., 2008). Therefore, this study highlighted the significance of thumbprints minutiae in assessing the level of developmental stress and instability among the Hausa population using FA. It was reported that fluctuating asymmetry is often used as a proxy to quantify developmental stressors and explore the effects of these developmental insults on individuals' health, fitness, and behavior (Benderlioglu, 2010). It may be recommended that this study be expanded to other digits and other populations in order to explore more about the pattern of the asymmetry in other digits and populations for better explanation of the phenomenon.

\section{CONCLUSION}

The presence of sexual dimorphism in thumbprint ridge minutiae was demonstrated in the present study. The leftward asymmetry was observed in both sexes in different types minutiae. Females were observed to exhibit directional type of asymmetry more than the males in this population.

\section{Acknowledgements:}

We thank all those who volunteered to participate in this research. Also to Sanusi Aminu who helped in the development of the software used as well as other technical assistance.

\section{Funding:}

This work is an extract of a Ph.D. dissertation which was sponsored by Bayero University Research Grant Unit and Tertiary Education Trust Fund (TETfund) of Nigeria.

\section{Conflict of Interest:}

The authors declare that there is no conflict of interest.

Authors' contributions: Adamu L .H: concepts, design, definition of intellectual content, literature search, data acquisition and analyses, manuscript preparation, editing and review. Ojo S.A: design, definition of intellectual content, manuscript preparation, editing and review. Danborno, B: design, data analyses, manuscript preparation, editing and review. Adebisi S. S: definition of intellectual content, manuscript preparation, editing and review. Taura M.G: definition of intellectual content, manuscript preparation, editing and review.

Barau, A. S. (2007). The Great Attractions of Kano. Research and Documentation publications. Research and Documentation Directorate, Government House Kano. ISBN 978-8109-33

Benderlioglu, Z. (2010). Fluctuating Asymmetry and Steroid Hormones: A Review. Symmetry, 2: 541-553 
BAJOPAS Volume 10 Number 1 June, 2017

Champod, C. and Margot, P.A. (1996). Analysis of minutiae occurrences on fingerprints - the search for non-combined minutiae, In: Proceedings of International Association of Forensic Sciences (IAFS), Tokyo, Japan..

Cummins, H., Waits, W. J. and McQuitty, J. T. (1994). The breadths of epidermal ridges on the finger tips and palms: a study of variations. American Journal of Anatomy, 68: 127-150

Cummins, H. and Midlo, C. (1943). Finger Prints, Palms and Soles, Blakiston, Philadelphia.

Galeotti, P., Sacchi, R. and Vicario, V. (2005): Fluctuating asymmetry in body traits increases predation risks: Tawny owl selection against asymmetric woodmice. Evolutionary Ecology, 19: 405-418.

Graham, J. H., Freeman, D. C. and Emlen, J. M. (1993). Developmental stability: a sensitive indicator of populations under stress. Pages 136-158 in WG Landis, JS Hughes, MA Lewis, eds. Environmental toxicology and risk assessment. American Society for Testing and Materials, Philadelphia

Graham, J. H., Emlen, J. M. and Freeman, D. C. (2003). Nonlinear dynamics and developmental instability. Pages $35-50$ in M Polak, ed. Developmental instability: causes and consequences. Oxford University Press, New York.

Graham, J. H., Emlen, J. M. Freeman, D. C., Leamy, L. J. and Kieser, J. A. (1998): Directional asymmetry and the measurement of developmental instability. Biology Journal of Linn Society, 64:1-16.

Gutie'rrez-Redomero, E., Galera, V., Martı'nez, J. M. and Alonso, C. (2007). Biological variability of the minutiae in the fingerprints of a sample of the Spanish population. Forensic Science International, 172: 98-105.

Jain, A. K. Chen, Y. and Demirkus, M. (2007). Pores and Ridges: High-Resolution Fingerprint Matching Using Level 3 Features, IEEE Transactions on Pattern Analysis and Machine Intelligence, 29 (1): 15-27

Jamison, C. S., Jamison, P. L., and Meier, R. J. (1994). Effect of prenatal testosterone administration on palmer dermatoglyphic intercore ridge counts of rhesus monkeys (Macaca mulatta). American Journal of Physical Anthropology, 94, 409-419.

Jamison, C. S., Meier, R. J. and Campbell, B. C. (1993). Dermatoglyphic asymmetry and testosterone levels in normal males. American Journal of Physcial Anthropology, 90, 185-198.

Koehler, N., Simmons, L. W., Rhodes, G.I. and Peters, M. (2004). The relationship between sexual dimorphism in human faces and fluctuating asymmetry. Proceeding of Royal Society of London B (Suppl.) 271: S233S236.

Kusuma Y. S., Babu B. V. and Naidu J. M. (2001). Asymmetry of finger ridge counts among four tribal populations of Andhra Pradesh, India. HOMO Journal of Comparative Human Biology, 52 (2), 110-116
Lewis, C., Pook, C. and Galloway, T. (2008). Reproductive toxicity of the water accommodated fraction (WAF) of crude oil in the polychaetes Arenicola marina (L.) and Nereis virens (Sars) Aquatic Toxicology, 90 73-81.

Malhotra, K. C., Majumdar, L. and Reddy, B. M. (1991). Regional variation in ridge count asymmetry on the hand. In Reddy BM, Roy SB, Sarkar BN (ed) Dermatoglyphics Today. IBRAD, ASI and ISI, Calcutta, 153-166.

Manning, J. T. (1995). Fluctuating asymmetry and body weight in men and women: implications for sexual selection. Ethology and Sociobiology, 16: 145-153.

Markow, T.A. and Martin, J. F. ( 1993). Inbreeding and developmental stability in a small human-population. Annals of Human Biology, 20: 389-394.

Martin, N., Jinks, J., Berry H. and Loesch, D. A. (1982). Genetical analysis of diversity and asymmetry in finger ridge counts Heredity 1982, 48:393-405

Møller, A. P. and Shykoff, J. A. (1999). Morphological developmental stability in plants: patterns and causes. International Journal of Plant Science, 160(suppl): S135-S146.

Møller, A. P. and Swaddle, J. P. (1997). Asymmetry, developmental stability, and evolution. Oxford University Press, New York. 291 pp.

Møller, A. P. and Cuervo, J. J. (2003). Asymmetry, size, and sexual selection: factors affecting heterogeneity in relationships between asymmetry and sexual selection. In Developmental instability: causes and consequences (ed. M. Polak), pp. 262-275. Oxford University Press.

Mooney, M. P., Siedel, M. I. and Gest, T. R. (1985). Prenatal stress and increase fluctuating asymmetry in the parietal bones of neonatal rats. American Journal of Physical Anthropology, 68: 131-134.

Mundorff, A. Z., Bartelink, E. J. and Murad, T. A. (2014). Sexual dimorphism in finger ridge breadth measurements: a tool for sex estimation from fingerprints. Journal of Forensic Sciences, 59(4): 891-897

Mustanski, B.S., Bailey, J., M. and Kaspar, S. (2002). Dermatoglyphics, handedness, sex, and sexual orientation. Archives of Sexual Behavior, 31(1), 113-112.

Nijhout, H. F. and Davidowitz, G. (2003). Developmental perspectives on phenotypic variation, canalization, and fluctuating asymmetry. Pages 3-13 in M Polak, ed. Developmental instability: causes and consequences. Oxford University Press, New York.

Okajima, M. (1970). Frequency of forks in epidermal ridge minutiae in the finger print. American Journal of Physical Anthropology, 32: 41-48.

Palmer, A. (1994). Fluctuating asymmetry analysis: a primer In: Developmental Instability:its origins and evolutionary implications (Edited by: TA M) Dordrecht: Kluwer, 335-364 
BAJOPAS Volume 10 Number 1 June, 2017

Palmer, A. R. and Strobeck, C. (1986). Fluctuating asymmetry: measurement, analysis, and pattern. Annual Review of Ecology and Systemtemic 17:391-421.

Palmer, A. R. and Strobeck, C. (2003). Fluctuating asymmetry analysis revisited. In: Polak, $\mathrm{M}$. (Ed.), Developmental Instability; Causes and Consiquences, Oxford University Press, New York, 279-319

Parsons, P. A. (1990). Fluctuating asymmetry: an epigenetic measure of stress. Biological Reviews, 65:131-145.

Parsons, P. A. (1992). Fluctuating asymmetry: A biological monitor of environmental and genomic stress. Heredity, 68: 361-364.

Siegel, M. I. Doyle, W. J. and Kelly, C. (1977). Heat, stress, fluctuating asymmetry, and prenatal selection in the laboratory rat. American Journal of Physical Anthropology, 46: 121126.
Siegel, M. I. and Smookler, H. H. (1973). Fluctuating dental asymmetry and auditory stress. Growth, 37:35-39.

Umar, K. B., Danborno, B., Olorunshola, K. V. and Adamu, L.H, (2016). Sexual dimorphism in hand grip strength and hand dimensions among Hausas. Annals of Bio-anthropology, 4 (2); 90-95

Van Valen, L. (1962). A study of fluctuating asymmetry, Evolution, 16: 125-142.

Velickovic, M. (2007). Measures of the developmental stability, body size and body condition in the black-striped mouse (Apodemus agrarius) as indicators of a disturbed environment in northern Serbia. Belgian Journal of Zoology, 137: 147-156. 